Jin Li, Yan Chen, Ziqing Wu, Yali Liu, Dachuan Yin* and Zhenyu Zuo

\title{
The crystal structure of 2-phenyl-4,6-bis(prop-2- yn-1-yloxy)-1,3,5-triazine, $\mathrm{C}_{15} \mathrm{H}_{11} \mathrm{~N}_{3} \mathrm{O}_{2}$
}

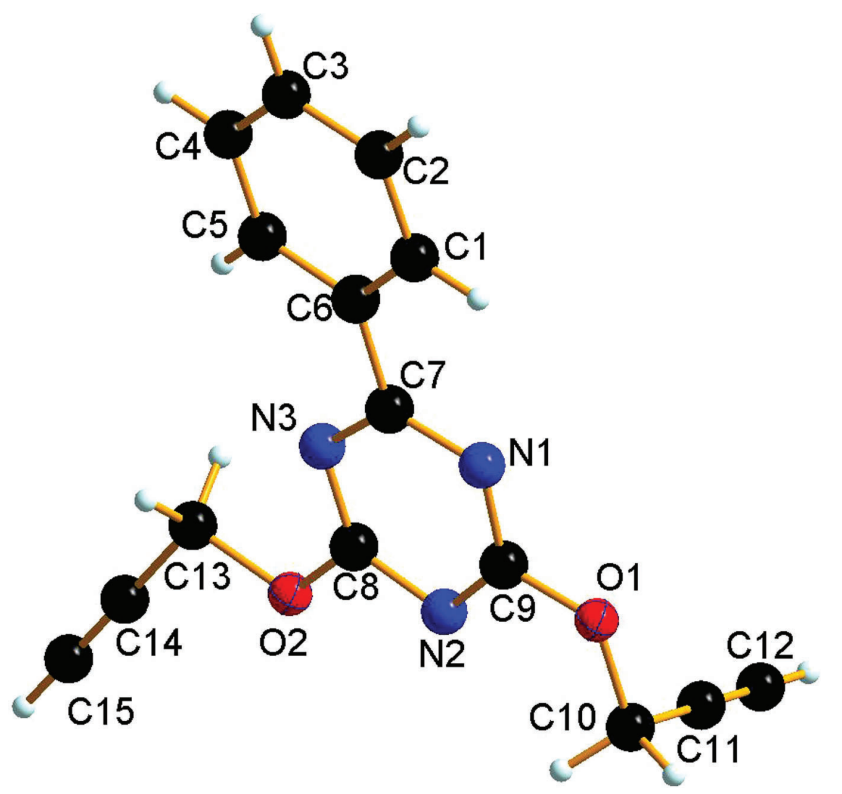

https://doi.org/10.1515/ncrs-2019-0733

Received September 29, 2019; accepted November 22, 2019; available online December 13, 2019

\section{Abstract \\ $\mathrm{C}_{15} \mathrm{H}_{11} \mathrm{~N}_{3} \mathrm{O}_{2}, \quad$ triclinic, $P \overline{1} \quad$ (no. 2), $\quad a=8.4680(5) \AA$, $b=9.7578(5) \AA, \quad c=10.2101(6) \AA, \quad \alpha=104.578(5)^{\circ}$, $\beta=111.882(6)^{\circ}, \quad \gamma=106.589(5)^{\circ}, \quad V=686.77(8) \AA^{3}, \quad Z=2$, $R_{\mathrm{gt}}(F)=0.0394, w R_{\text {ref }}\left(F^{2}\right)=0.1261, T=250(2) \mathrm{K}$.}

CCDC no.: 1956210

\footnotetext{
*Corresponding author: Dachuan Yin, Institute for Special Environmental Biophysics, Key Laboratory for Space Bioscience and Space Biotechnology, School of Life Sciences, Northwestern Polytechnical University, Xi'an 710072, Shaanxi, P.R. China; and College of Pharmacy, Shaanxi University of Chinese Medicine, Xi'an, Shaanxi 712046, P.R. China, e-mail: yindc@nwpu.edu.cn Jin Li, Ziqing Wu and Yali Liu: Institute for Special Environmental Biophysics, Key Laboratory for Space Bioscience and Space Biotechnology, School of Life Sciences, Northwestern Polytechnical University, Xi'an 710072, Shaanxi, P.R. China; and College of Pharmacy, Shaanxi University of Chinese Medicine, Xi'an, Shaanxi 712046, P.R. China. https://orcid.org/0000-0002-7847-8616 (J. Li) Yan Chen and Zhenyu Zuo: College of Pharmacy, Shaanxi University of Chinese Medicine, Xi’an, Shaanxi 712046, P.R. China
}

The molecular structure is shown in the figure. Table 1 contains crystallographic data and Table 2 contains the list of the atoms including atomic coordinates and displacement parameters.

Table 1: Data collection and handling.

\begin{tabular}{ll}
\hline Crystal: & Yellow block \\
Size: & $0.18 \times 0.16 \times 0.12 \mathrm{~mm}$ \\
Wavelength: & Cu $K \alpha$ radiation $(1.54184 \AA$ A $)$ \\
$\mu:$ & $0.72 \mathrm{~mm}^{-1}$ \\
Diffractometer, scan mode: & SuperNova, $\omega$ \\
$\theta_{\text {max }}$, completeness: & $76.5^{\circ},>99 \%$ \\
$N\left(h k l_{\text {measured }}, N\left(h k l l_{\text {unique }}, R_{\text {int }}:\right.\right.$ & $6581,2857,0.013$ \\
Criterion for $I_{\text {obs }}, N(h k l)_{\text {gt }}:$ & $I_{\text {obs }}>2 \sigma\left(I_{\text {obs }}\right), 2328$ \\
$N(\text { param })_{\text {refined }}:$ & 182 \\
Programs: & CrysAlis ${ }^{\text {PRO }[1], \text { SHELX [2] }}$ \\
\hline
\end{tabular}

\section{Source of material}

To ethyl ether $(150 \mathrm{~mL})$, were added $\mathrm{Mg}(3.84 \mathrm{~g}, 0.160 \mathrm{~mol})$ and $\mathrm{I}_{2}(1.02 \mathrm{~g}, 0.004 \mathrm{~mol})$ under the atmosphere of $\mathrm{N}_{2}$. After the mixture was stirred for $10 \mathrm{~min}$, bromobenzene $(25 \mathrm{~g}$, $0.160 \mathrm{~mol}$ ) was added dropwisely. When Mg disappeared, the reaction mixture was refluxed for $30 \mathrm{~min}$ and then cooled to $-15{ }^{\circ} \mathrm{C}$. To the above solution of $\mathrm{PhMgBr}$ was added a solution of 2,4,6-trichloro-1,3,5-triazine ( $32 \mathrm{~g}, 0.175 \mathrm{~mol}$ ) in tetrahydrofuran in $30 \mathrm{~min}$. After $2 \mathrm{~h}$, the reaction was quenched by $20 \mathrm{~mL}$ of ethanol. The final mixture was filtered and the filtrate was evaporated to get a yellow solid, which was purified by chromatography on silica gel to get the 2,4dichloro-6-phenyl-1,3,5-triazine (27.85 g, yield $77 \%$ ) as a white solid. To the solution of 2,4-dichloro-6-phenyl-1,3,5-triazine ( $4.52 \mathrm{~g}, 0.02 \mathrm{~mol}$ ) in $120 \mathrm{~mL}$ of tetrahydrofuran was added $\mathrm{K}_{2} \mathrm{CO}_{3}(5.52 \mathrm{~g}, 0.04 \mathrm{~mol}$ ) and prop-2-yn-1-ol (2.25 g, $0.04 \mathrm{~mol})$. The reaction system was refluxed for $24 \mathrm{~h}$ and then filtered to get a brown solution. The solvent was evaporated under reduced pressure to get a yellow solid which was purified by chromatography on silica gel to afford 2-chloro-4-(prop2-yn-1-yloxy)-6-phenyl-1,3,5-triazine as a light yellow solid. (2.75 g, 52\%). ${ }^{1}$ H-NMR (400 MHz, chloroform-d)): $\delta$ [ppm] 7.59 (d, $J=8 \mathrm{~Hz}, 2 \mathrm{H}$ ), 7.53-7.49 (m, 3H), 5.15 (s, 4H), 2.57 (s, $2 \mathrm{H}$ ). The crystals were obtained by recrystallization from ethyl acetate at room temperature. 
Table 2: Fractional atomic coordinates and isotropic or equivalent isotropic displacement parameters $\left(\AA^{2}\right)$.

\begin{tabular}{lrrrr}
\hline Atom & $\boldsymbol{x}$ & $\boldsymbol{y}$ & $\boldsymbol{Z}$ & $\boldsymbol{U}_{\text {iso }}{ }^{*} U_{\text {eq }}$ \\
\hline O1 & $0.26180(14)$ & $0.89380(11)$ & $0.61705(11)$ & $0.0687(3)$ \\
O2 & $0.62462(13)$ & $0.72655(10)$ & $0.92966(10)$ & $0.0631(3)$ \\
N1 & $0.22943(15)$ & $0.64959(12)$ & $0.51991(12)$ & $0.0562(3)$ \\
N2 & $0.45351(15)$ & $0.81844(12)$ & $0.78189(12)$ & $0.0563(3)$ \\
N3 & $0.41981(14)$ & $0.55814(11)$ & $0.67794(11)$ & $0.0531(3)$ \\
C1 & $0.0410(2)$ & $0.34891(18)$ & $0.27641(15)$ & $0.0683(4)$ \\
H1 & -0.0012 & 0.4256 & 0.2608 & $0.082^{*}$ \\
C2 & $-0.0468(2)$ & $0.1998(2)$ & $0.15944(17)$ & $0.0851(5)$ \\
H2 & -0.1485 & 0.1759 & 0.0646 & $0.102^{*}$ \\
C3 & $0.0144(3)$ & $0.0876(2)$ & $0.1819(2)$ & $0.0892(6)$ \\
H3 & -0.0463 & -0.0130 & 0.1027 & $0.107^{*}$ \\
C4 & $0.1634(3)$ & $0.12125(19)$ & $0.3189(2)$ & $0.0849(5)$ \\
H4 & 0.2052 & 0.0440 & 0.3332 & $0.102^{*}$ \\
C5 & $0.2528(2)$ & $0.26881(16)$ & $0.43661(18)$ & $0.0690(4)$ \\
H5 & 0.3553 & 0.2916 & 0.5305 & $0.083^{*}$ \\
C6 & $0.19101(17)$ & $0.38337(14)$ & $0.41604(14)$ & $0.0551(3)$ \\
C7 & $0.28490(16)$ & $0.53931(13)$ & $0.54374(13)$ & $0.0498(3)$ \\
C8 & $0.49416(17)$ & $0.69758(14)$ & $0.78949(13)$ & $0.0516(3)$ \\
C9 & $0.32045(18)$ & $0.78521(15)$ & $0.64352(15)$ & $0.0547(3)$ \\
C10 & $0.3547(2)$ & $1.04671(16)$ & $0.74137(19)$ & $0.0701(4)$ \\
H10A & 0.3853 & 1.0356 & 0.8395 & $0.084^{*}$ \\
H10B & 0.2698 & 1.0985 & 0.7269 & $0.084^{*}$ \\
C11 & $0.5252(2)$ & $1.14199(18)$ & $0.7470(2)$ & $0.0739(4)$ \\
C12 & $0.6599(3)$ & $1.2194(2)$ & $0.7483(3)$ & $0.1089(7)$ \\
H12 & 0.7683 & 1.2817 & 0.7494 & $0.131^{*}$ \\
C13 & $0.6787(2)$ & $0.60103(16)$ & $0.94380(15)$ & $0.0637(4)$ \\
H13A & 0.7487 & 0.5858 & 0.8879 & $0.076^{*}$ \\
H13B & 0.5672 & 0.5033 & 0.9011 & $0.076^{*}$ \\
C14 & $0.79587(19)$ & $0.64587(17)$ & $1.10754(16)$ & $0.0640(4)$ \\
C15 & $0.8877(2)$ & $0.6802(2)$ & $1.23930(18)$ & $0.0789(5)$ \\
H15 & 0.9614 & 0.7077 & 1.3451 & $0.095^{*}$ \\
\hline & & & &
\end{tabular}

\section{Experimental details}

The hydrogen atoms were placed at calculated positions as riding atoms.

\section{Comment}

As an important unsaturated unit, the ethynyl group can be used to construct big $\pi$-conjugated systems, which can be widely applied into organic electronics, such as high performance organic field-effect transistors [3, 4], organic solar cells [5], organic light-emitting materials [6], organic liquid crystal materials [7] and so on. The $s$-triazine (1,3,5-triazine) ring is a remarkable building block to generate supramolecular interactions and an important unit to construct various nonlinear optical devices [8]. So designing and synthesizing of novel triazine derivatives with ethynyl conjugated units is a charming direction in organic synthesis. The structure of the title compound was characterized by ${ }^{1} \mathrm{H}-\mathrm{NMR}$ and X-ray diffraction.
In the title molecule, the typical bond length [9] of C1-C6,

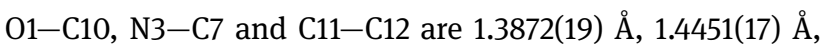
1.3428(15) $\AA$ and 1.167(3) $\AA$, respectively. The torsion angle of $\mathrm{C} 5-\mathrm{C} 6-\mathrm{C} 7-\mathrm{N} 3$ is $4^{\circ}$, which demonstrated that the benzene ring and the 1,3,5-triazine ring are not exactly in the same plane ( $c f$. the figure). Similar to the packing of other triazines weak non-classical hydrogen bonds [10] were observed. In the molecular packing, there are obvious $\pi-\pi$ stacking interactions between the adjacent aromatic moieties. The distance between adjacent aromatic moieties is less than $3.447 \AA$.

Acknowledgements: We acknowledge the supports by National Key R\&D program of China (2018YFC1706903), the Project of Shaanxi Key Laboratory of Basic and New Herbal Medicament Research (NO: 2017KF05) (NO: 19JS019), the National Natural Science Foundation of China (NO: 81403101), the Subject Innovation Team of Shaanxi University of Chinese Medicine (NO. 2019-YL11), Key Discipline of TCM Pharmaceutical Engineering in Shaanxi Administration of Traditional Chinese Medicine (NO: 303061107) (NO: 132018004).

\section{References}

1. Dolomanov, O. V.; Bourhis, L. J.; Gildea, R. J.; Howard, J. A. K.; Puschmann, H.: OLEX2: a complete structure solution, refinement and analysis program. J. Appl. Crystallogr. 42 (2009) 339-341.

2. CrysAlis ${ }^{\text {PRO }}$, Oxford diffraction Oxford.

3. Song, H. G.; Kim, Y.; Park, S.-M.; An, T. K.; Kwon, S.-K.; Park, C. E.; Kim, Y.-H.: Synthesis, characterization, and transistor applications of new linear small molecules: naphthyl-ethynyl-anthracene-based small molecules containing different alkyl end group. Dyes Pigments 131 (2016) 349-355.

4. Jo, S.; Shin, J.; Bae, S. Y.; Kim, K. H.; Lee, T. W.; Son, S.; Kim, K.; Choi, D. H.: 5-(Anthracene-9,10-diyl)bis(ethyne-2,1-diyl)bis (2-hexylthiophene) derivatives bearing 5-ethynyl-5-hexyl-2,2bithiophene and 2-ethynyl-5-hexylthieno[3,2-b]thiophene: thin film transistors and photovoltaic applications. Synth. Met. 161 (2011) 833-843.

5. Yu, C.; Xu, Y.; Liang, S.; Jiang, X.; Feng, G.; Li, C.; Li, W.: Ethynyl-linked perylene bisimide based electron acceptors for non-fullerene organic solar cells. Chin. Chem. Lett. 29 (2018) 325-327.

6. Bernal, W.; Barbosa-García, O.; Aguilar-Granda, A.; Pérez-Gutiérrez, E.; Maldonado, J.-L.; Percino, M.; Rodríguez-Molina, B.: White organic light emitting diodes based on exciplex states by using a new carbazole derivative as single emitter layer. Dyes Pigments 163 (2019) 754-760.

7. Srinivasa, H. T.; HariPrasad, S.: 4-[2-(Trimethylsilyl)ethynyl] benzoates: synthesis and evaluation for mesomorphic properties of some novel calamitic molecules. J. Organomet. Chem. 774 (2014) 19-25. 
8. Lee, H.; Kim, D.; Lee, H.-K.; Qiu, W.; Oh, N.-K.; Zin, W.-C.; Kim, K.: Discotic liquid crystalline materials for potential nonlinear optical applications: synthesis and liquid crystalline behavior of 1,3,5-triphenyl-2,4,6-triazine derivatives containing achiral and chiral alkyl chains at the periphery. Tetrahedron Lett. 45 (2004) 1019-1022.
9. Eçik, E. T.; Şenkuytu, E.; Çoşut, B.: Novel Bodipy- triazine conjugates: synthesis and the generation of singlet oxygen. Dyes Pigments 143 (2017) 455-462.

10. Zuo, Z.; Lei, F.; Song, X.; Wang, L.: The crystal structure of $N$, $N$-diethyl-4,6-bis(naphthalen-2-yloxy)-1,3,5-triazin-2-amine, $\mathrm{C}_{27} \mathrm{H}_{24} \mathrm{~N}_{4} \mathrm{O}_{2}$. Z. Kristallogr. NCS 233 (2018) 1083-1085. 